\title{
Perioperative Volume Replacement with Hydroxyethyl Starch 130/0.4 vs Ringer's Lactate in Abdominal Surgery: A Comparative Study of their Effect on Cytokines and Matrix Metalloproteinases P Matsota $^{1}$, V Skaftourou ${ }^{2}$, A Palgimezi ${ }^{2}$, C Kaliouli- Antonopoulou ${ }^{3}$, H Pappa $^{3}$, $\mathrm{N}$ Georgogiannis ${ }^{4}$, G Kostopanagiotou ${ }^{1}$
}

\begin{abstract}
Objective: Fluid therapy may affect inflammatory response to surgery. We investigated the effect of volumereplacement with hydroxyethyl starch (HES) or Ringer's Lactate (RL) on cytokines and matrix metalloproteinases (MMPs) postoperative levels.
\end{abstract}

Methods: Forty-seven patients undergoing moderate or major abdominal surgery under general anaesthesia were allocated to receive intraoperatively and 24 hours postoperatively either only RL (RL-group, $n=25$ ) or HES 130/0.4 combined with RL (HES-group, $n=22$ ) for volume replacement. Blood samples were collected before anaesthesia induction, at the end of operation and 24 hours postoperatively and Cytokines (IL-6, IL-8) and MMPs (MMP-9, MMP-13) were measured.

Results: Demographics, operations and haemodynamics were similar in two groups. RL-group received in total $3983 \pm 888 \mathrm{ml}$ of RL and HES-group $1068 \pm 242 \mathrm{ml}$ of HES 130/0.4 plus $2033 \pm 672 \mathrm{ml}$ of RL, per patient respectively. In all operations, 24 hours postoperatively, IL-8 serum levels were significantly lower in HES-group $(14.6 \pm 6.9 \mathrm{pg} / \mathrm{ml}$ vs $23.2 \pm 13.9 \mathrm{pg} / \mathrm{ml}, \mathrm{p}<0.05)$. In major operations, apart from IL-8, MMP-9 was also affected ([HES-group: $128.3 \pm 11.8 \mathrm{ng} / \mathrm{ml}]$ vs [RL-group: $131.8 \pm 7.1 \mathrm{ng} / \mathrm{ml}] ; \mathrm{p}<0.05)$.

Conclusion: HES volume replacement compared to RL presented a lower increase of IL-8 after abdominal surgery. This protective effect was more intensive in major surgeries since both IL-8 and MMP-9 were affected.

Keywords: Cytokines, fluid therapy, hydroxyethyl starch derivatives, isotonic solutions, metalloproteinases

From: ${ }^{1} 2^{\text {nd }}$ Department of Anaesthesiology, School of Medicine, National and Kapodistrian University of thens, Attikon Hospital, Athens, Greece, ${ }^{2}$ Department of Anaesthesiology, General Hospital of Nikaia- Pireus, Greece, ${ }^{3}$ Immunology Department, General Hospital of Nikaia- Pireus, Greece, ${ }^{4}$ Gynaecology Department, General Hospital of Nikaia- Pireus, Greece

Correspondence: Dr P Matsota, School of Medicine, National and Kapodistrian University of Athens "Attikon" Hospital, 1 Rimini Str Chaidari Postal Code 12462, Athens Greece. Fax: + +30-210-5326413

e-mail: matsota@yahoo.gr 


\section{INTRODUCTION}

Surgery may induce systemic inflammatory response by releasing of potent inflammatory mediators such as cytokines and matrix metalloproteinase. Experimental and clinical data indicate that the kind of perioperative fluid therapy may affect this immune response (1- 5).

In our study we tested the hypothesis that perioperative volume replacement with hydroxyethyl starch (HES) may attenuate the inflammatory response to elective abdominal surgery compared to Ringers lactate (RL) fluid therapy. For this purpose the levels of both cytokines and matrix metalloproteinases were monitored the first postoperative 24 hours.

\section{SUBJECTS AND METHODS}

Study design

The study protocol was approved by the Scientific Councils of University Hospital Attikon and General Hospital of Pireus “Ag. Panteleimon” (protocol numbers: 10/21-10-2008, Chairperson Prof. D. Kremastinos and 10/24-07-2008, Chairperson G. Antipas). The study was registered at Clinical Trials.dov (ID: NCT01880190) and conducted in accordance with the Helsinki Declaration. After obtaining written informed consent, 47 adult patients aged 18-76 years of ASA I-II undergoing elective moderate or major abdominal surgery under general anaesthesia were included in this prospective randomized blind designed study.

Exclusion criteria were: severe systematic disease, bacterial- viral infection, active inflammation, malignant neoplasia, morbid obesity, extreme muscular activity, chronic use of corticosteroids, $\beta$ - blockers or non-steroid anti-inflammatory drugs, and known allergy to colloids or to any other drug used in the study. 
A standard protocol of general anaesthesia was used with propofol, fentanyl, rocuronium, remifentanil, and sevoflurane in $\mathrm{O}_{2} / \mathrm{N}_{2} \mathrm{O}$. Insensible losses were maintained with $\mathrm{RL}$ at a standard rate based on Holliday-Segar equation. Intraoperative monitoring included trans-oesophageal thermometer, heart rate (HR), Systolic (SAP), Diastolic (DAP) \& Mean arterial blood pressure (MAP) and Stroke Volume Variation (SVV) using the Flow Trac/Vigileo ${ }^{\mathrm{TM}}$ devise.

Patients were prospectively randomized by a computerized random number generator to receive for intravascular volume replacement either exclusively Ringer's Lactate (RL-group, n=25), or 6\% hydroxyethyl starch 130/0.4 (Voluven; Fresenius Kabi) (HES-group, n=22) to maintain MAP within $\pm 20 \%$ of the pre-operative values and SVV between 5-15\%. Postoperative analgesia included paracetamol and pethidine. Postoperative monitoring in the ward included ECG, noninvasive haemodynamic measurements, urine output, and temperature. The development of renal impairment during the first 3 postoperative months was also tested via telephone interview.

\section{Measurements}

Blood samples were collected at predefined time points (before anaesthesia induction [base line], at the end of operation and 24 hours postoperatively) and measurements of Cytokines ([interleukins; IL] [IL-6, IL-8]), Metalloproteinases ([MMPs] [MMP-9, MMP-13]), Tissue Inhibitor of Metalloproteinase (TIMP-1) and the soluble Intercellular Adhesion Molecule-1 (sICAM-1) were performed. The titters of IL-6, IL-8, sICAM-1, MMP-9, MMP-13 and TIMPs-1 were determined by solid phase immunosorbent assays. They were used commercially available kits (Bender Medsystem, Austria). All results represented the means from duplicate measurements. Sample collection, serum storage and test instructions were rigidly performed. The reference values for any method used derived from randomly selected apparently healthy donors and were for IL-6 mean of detectable: $5.8 \mathrm{pg} / \mathrm{ml}$ and range: $\mathrm{n}$. d. (non-detected) $-12.7 \mathrm{pg} / \mathrm{ml}$ with $47 \%$ detectable, IL-8 mean of detectable $114 \mathrm{pg} / \mathrm{m}$ and range: $34.8-666.4 \mathrm{pg} / \mathrm{ml}$ with $22.5 \%$ detectable, MMP-9 detectable range: 2-139.4ng/ml, MMP-13 detectable range: n.d.-9.7ng/ml, TIMPs-1 mean of 
detectable $172 \pm 130 \mathrm{ng} / \mathrm{ml}$ with range: $11-743 \mathrm{ng} / \mathrm{ml}$ and sICAM-1 mean of detectable $504+171 \mathrm{ng} / \mathrm{ml}$ with range: $302-1115 \mathrm{ng} / \mathrm{ml}$.

$\mathrm{Hct}, \mathrm{Hb}, \mathrm{WBC}$, urea, creatinine, and C-reactive protein (CRP) were also measured at the same time points.

\section{Outcomes}

Primary outcomes of the study included IL-6, IL-8, MMP-9, MMP-13, TIMP-1 and sICAM-1 changes during the first 24 postoperative hours.

Secondary endpoints included the investigated haemodynamic and haematological variables.

\section{Statistical analyses}

All data were presented as mean \pm standard deviation (SD). Independent- samples T- Tests were used for statistical interpretation. Kolmogorov-Smirnov tests were used for testing normality of the distributions. Where distribution of normality was not confirmed, non parametric test, such as Wilcoxon, was used. A p less than 0.05 was considered significant $(\alpha=0.05)$. A priori power analysis has been taken place $\mathrm{G}^{*}$ Power software, in order required sample to be defined according to power (1- $\beta$ err prob) 0.80 approximately. The number of patients required in each group was determined on data obtained from previous studies $[1,2]$. We considered the bio-markers in exam IL-8, IL-6, ICAM-1, MMP-9, TIMPs-1. Based on this assumption, 32 (16 per group) patient were required. Categorical data were compared using Chi-Square analysis. P-values $<0.05$ were considered statistically significant. Data were analysed using IBM SPSS 19.0.

\section{RESULTS}

Forty-seven patients were included in the study: 23 underwent elective major abdominal surgery (total abdominal hysterectomy with bilateral salpingectomy) and 24 moderate abdominal operations (9 inguinal hernia, 15 laparoscopic cholecystectomy). 
All patients completed the study protocol. There were no significant differences between the two groups with respect to demographics and perioperative data. Patients in RL-group received significantly increased fluid volume and had higher total urine output (Table 1).

There was no difference between two groups in haemodymanics and haematological variables

(Table 2) and in body temperature, CRP and WBC values, while no patient developed renal impairment three months later.

We also analyzed the sub-group that included the patients who underwent only the major surgeries and received either HES plus RL or only RL. Similar results regarding demographics, perioperative data, fluid volume, urine output (Table 3), haemodymanics and haematological variables were revealed in this sub-group (Table 4).

During the study period, all the investigated bio-markers increased significantly in all participants [(peak values $24 \mathrm{~h}$ after surgery) $22.9 \pm 18.2 \mathrm{pg} / \mathrm{ml}$ IL-6; $23.2 \pm 13.9 \mathrm{pg} / \mathrm{ml}$ IL-8; $136.3 \pm 14.5 \mathrm{ng} / \mathrm{ml} \quad$ MMP-9; $5.6 \pm 1.7 \mathrm{ng} / \mathrm{ml} \quad$ MMP-13; $625.50 \pm 708.77 \mathrm{ng} / \mathrm{ml} \quad$ TIMPs-1; $411 \pm 167.3 \mathrm{ng} / \mathrm{ml}$ sICAM-1 in the RL group and $28.8 \pm 32.8 \mathrm{pg} / \mathrm{ml} \mathrm{IL-6,} 14.6 \pm 6.9 \mathrm{pg} / \mathrm{mp}$ IL-8, 127.8 $\pm 12.4 \mathrm{ng} / \mathrm{ml} \quad$ MMP-9, $4.8 \pm 1.4 \mathrm{ng} / \mathrm{ml} \quad$ MMP-13, 527.36 $\pm 124.06 \quad \mathrm{ng} / \mathrm{ml} \quad$ TIMPs-1, 439.7 $\pm 159.2 \mathrm{ng} / \mathrm{ml}$ sICAM-1 in the HES group]. IL-8 in RL-group was significantly higher than that in HES-group (p-value=0.001) (Figure 1). MMP-13 was also increased more in RL-group, but without achieving statistical significance ( $\mathrm{p}$-value $=0.095$ ).

In the sub-group of the major surgeries, RL-group presented significantly higher values than HES-group $24 \mathrm{~h}$ postoperatively with respect to IL-8 ([21.4 $\pm 15.2 \mathrm{pg} / \mathrm{ml}$ in RL-group and $15.4 \pm 7.2$ $\mathrm{pg} / \mathrm{ml} \mathrm{IL-8} \mathrm{in} \mathrm{HES-group]} \mathrm{(p-value=0.008)} \mathrm{and} \mathrm{MMP-9}[131.8 \pm 7.1 \mathrm{ng} / \mathrm{ml}$ in RL-group and 128.3 $\pm 11.8 \mathrm{ng} / \mathrm{ml}$ in HES-group]) (p-value=0.026) (Figures 2 and 3, respectively).

\section{DISCUSSION}

Our study revealed that perioperative volume replacement with HES compared to Ringer's Lactate was associated with less inflammatory response to abdominal surgery with respect to cytokines and 
MMPs postoperative levels. Although an increase of all investigated biomarkers was observed in both groups, the group received HES presented a lower increase comparing to RL. However, this difference was statistically significant only with regard to IL-8. On the other hand, in major abdominal surgery more biomarkers were affected, since both IL-8 and MMP-9 have shown significantly less increase in those patients treated with HES. Noticeably, secondary outcomes of our study including CRP and WBC were similarly altered in both groups, while renal function was not influenced by the type of fluid therapy both during the immediate postoperative period and three months later.

In accordance with previous data, we found that IL8 was less increased in HES-group compared to RL-group (5). IL-8 increases the affinity of leukocytes integrins for their ligands on endothelium (6) and promotes endothelial leak independent of neutrophils, via a mechanism involving protein synthesis (7). These data are concordant with the hypothesis that HES can affect the endothelium architecture and function. It is worth to mention that in our study IL-8 was increased not only in the major operations but also in the less severe ones such as laparoscopic cholecystectomy and inguinal hernia repair, thus we can assume that it is a very sensitive bio marker.

IL-6 has a generalized role to the cascade of inflammation, with non-specific action on the structure and function of the endothelium. In our study, IL-6 increased in both groups, and especially in RL-group but without achieving significant difference. Similar changes were observed with CRP indicating that with the use of HES the inflammatory response seems to be weaker compared to RL. Similar results have been reported by two studies performed in cardiac surgery $(5,8)$.

Several studies in vitro and in animals showed that HES attenuated inflammatory response by influence neutrophil adhesion to the endothelium, infiltration and migration interacting with 
ICAM-1 $(3,9)$. However, in our study we did not find any difference between the two groups with respect to sICAM-1changes.

MMP-9 is produced by inflammatory cells and degranulated to degrade type IV collagen (1, 6). Previous studies have shown that HES selectively inhibited MMP-9's activity in vitro, while in vivo induced lower MMP-9's increase after major abdominal surgery comparing to crystalloids with no significant effect on its natural inhibitor (TIMP-1). The net result was the reduction of MMP-9's activity (1). Our results are in accordance with these data only with regard to the major operations, thus we can assume that MMPs levels are directly depended on the severity of surgery. Other studies conclude that different volume replacement solutions might have variable effect on the release of MMP-9, depending on the present inflammatory surroundings (10).

MMP-13 expression is associated with severe chronic inflammation and with the development of chronic wounds (11). We found that the kind of perioperative fluid did not influence significantly MMP-13' levels, though a tendency of higher increase was shown in RLgroup. Further investigation is needed to clarify fluids' impact on MMP-13, given that there are no relevant studies to compare our findings.

TIMPs are naturally occurring proteins that specifically inhibit MMPs, thus maintaining balance between matrix destruction and formation. Similarly to previous reported data, we did not find any significant difference in TIMP-1 between the two investigated groups (1).

Our study has several interesting points to comment compared to the above mentioned studies: we measured contemporaneously more bio-markers involved differently in the inflammation cascade; we had a sufficient number of patients in exam in confront to the majority of the studies published till now; and we used a tight haemodymanic monitoring to guide volume replacement. However, our study has some limitations: elderly patients were not included; we did not investigate the clinical long term outcome with regard to inflammation; and in the group of major operations the number of patients involved was small. Thus, further investigation is needed 
to explore our results in high risk patients and/or correlate them with patient long term clinical outcome.

\section{CONCLUSION}

In conclusion, our study demonstrated that HES 130/0.4 intra- and postoperative volume replacement compared to pure RL fluid therapy seemed to attenuate the inflammatory response to elective abdominal surgery affecting less IL-8. This protective effect was more intensive in those patients who underwent major surgeries, since more biomarkers were affected, including both IL8 and MMP-9.

\section{ACKNOWLEDGMENTS}

This study was accomplished in Attikon Hospital and in General Hospital of Nikaia- Pireus in Greece.

\section{AUTHORS’ NOTE}

P. Matsota and V. Skaftourou motivated the study and contributed equally in the study design, patient consultation, collecting data, analysis of data and writing paper. A. Palgimezi participated in study design and patient consultation. C. Kaliouli-Antonopoulou and H. Pappa provided laboratory measurements and participated in the writing paper. N. Georgogiannis participated in patient consultation and collecting data. G. Kostopanagiotou participated in study design and writing paper. The authors declare that they have no conflicts of interest.

\section{REFERENCES}


1. Volta CA, Alvisi V, Campi M, Marangoni E, Alvisi R,Castellazzi M et al. Influence of different strategies of volume replacement on the activity of matrix metalloproteinases. Anesthesiology 2007; 106: 85-91.

2. Boldt J, Muller M, Heesen M, Neumann K, Hempelmann GG. Influence of different volume therapies and pentoxifylline infusion on circulating soluble adhesion molecules in critically ill patients. Critical Care Medicine 1996; 24: 385- 391.

3. Nohé B, Johannes T, Reutershan J, Rothmund A, Haeberle HA, Ploppa A. et al. Synthetic colloids attenuate leukocyte-endothelial interactions by inhibition of integrin function. Anesthesiology 2005; 103: 759-767.

4. Volta CA, Trentini A, Farabegoli L, Manfrinato MC, Alvisi V, Dallocchio F et al. Effects of two different strategies of fluid administration on inflammatory mediators, plasma electrolytes and acid/base disorders in patients undergoing major abdominal surgery: a randomized double blind study. Journal of inflammation 2013; 10: 29.

5. Öztürk T, Onur E, Cerrahoğlu M, Calgan M, Nizamoglu F, Civi M. Immune and inflammatory role of hydroxyethyl starch 130/0.4 and fluid gelatin in patients undergoing coronary surgery. Cytochine 2015; 74: 69-75.

6. Abbas AK, Lichman AH. Cytokines. In: Elsevier, editor. Cellulare and Molecular Immunology. $6^{\text {th }}$ ed. Philadelphia,USA: Saunders Elsevier; 2007: 248-249.

7. Biffl WL, Moore EE, Moore FA, Carl VS, Franciose RJ, Banerjee A. Interleukin-8 increases endothelial permeability independent of neutrophils. J Trauma 1995; 39: 98-102.

8. Liou HL, Shih CC, Chao YF, Lin NT, Wang SH, Chen HI. Inflammatory response to colloids compared to crystalloid priming in cardiac surgery patients with cardiopulmonary bypass. Chinese Journal of Physiology 2012; 55: 210-218.

9. Michael t. Handrigan, Alan R. Burns. Hydroxyethyl Starch inhibits neutrophil adhesion and transendothelial migration. Shock 2005;24: 434-439. 
10. Trentini A, Bellini T, Manfrinato MC, Dallocchio F, Fainardi E, Alvisi R et al. Balanced and unbalanced solutions modulate the release of matrix Metalloproteinase-9 (MMP-9) from neutrophils in response to inflammatory stimuli: an in vitro study. Inflammation Research 2014; 63: 325-328.

11. Airola K, Johansson AL, Kariniemi AL, Kahari VM, Saarialho-Kere UK. Human collagenase-3 is expressed in malignant squamous epithelium of the skin. J Invest Dermatol 1997; 109: 225-231.

Table 1. Demographics and perioperative data

$\begin{array}{lll}\underset{(n=22)}{\text { HES-group }} & \begin{array}{l}\text { RL-group } \\ (\mathrm{n}=25)\end{array} & \text { p-value } \\ \end{array}$




\begin{tabular}{llll}
\hline Age (years) & $45 \pm 15$ & $50 \pm 10$ & 0.184 \\
Sex (female/male) & $14 / 8$ & $18 / 7$ & 0.539 \\
Weight (kg) & $78 \pm 12$ & $78 \pm 12$ & 0.932 \\
Height (cm) & $167 \pm 8$ & $168 \pm 7$ & 0.714 \\
Duration of surgery (min) & $84 \pm 19$ & $89 \pm 20$ & 0.718 \\
Hysterectomy & 11 & 12 & 0.754 \\
Lap. colecystectomy & 9 & 6 & 0.754 \\
Inguinal hernia & 5 & 4 & 0.754 \\
RL tot (ml) & $2033 \pm 672$ & $3983 \pm 888$ & $0.007^{*}$ \\
HES tot (ml) & $1068 \pm 242$ & 0 & \\
Urine output tot (ml) & $2099 \pm 889$ & $3135 \pm$ & $0.008^{*}$ \\
& & 1512 & \\
\hline
\end{tabular}

Data are represented as number, mean + SD.*p-value $<0.05$.

Table 2. Haemodynamic and haematological variables in all operations

\begin{tabular}{|c|c|c|c|c|c|c|c|c|c|c|c|}
\hline & & $\begin{array}{l}\text { MAP } \\
(\mathrm{mmHg})\end{array}$ & $\begin{array}{l}\text { SVV } \\
(\%)\end{array}$ & $\begin{array}{l}\text { HR } \\
(\min \\
--1)\end{array}$ & $\begin{array}{l}\text { Creatinine } \\
\text { (mg/dl) }\end{array}$ & $\begin{array}{l}\text { Urea } \\
(\mathrm{mg} / \mathrm{dl})\end{array}$ & $\begin{array}{l}\text { Cl } \\
\text { creatinine } \\
(\mathrm{ml} / \mathrm{min})\end{array}$ & $\begin{array}{l}\text { Hb } \\
(\mathrm{g} / \mathrm{dl})\end{array}$ & $\begin{array}{l}\text { Hct } \\
(\%)\end{array}$ & $\begin{array}{l}\text { WBC } \\
\left(\mathrm{mm}^{-3}\right)\end{array}$ & $\begin{array}{l}\text { CRP } \\
\text { (mg/dl) }\end{array}$ \\
\hline \multirow[t]{6}{*}{$\mathbf{R L}$} & T0 & 90 & 9.3 & 72 & 0.7 & 26 & 66.22 & 13.5 & 39.6 & 10031 & 2.7 \\
\hline & & \pm 10 & \pm 1.8 & \pm 10 & \pm 0.2 & \pm 8 & \pm 24.59 & \pm 1.9 & \pm 7.4 & \pm 1378 & \pm 2 \\
\hline & T1 & 88 & 8.6 & 67 & 0.8 & 29 & 71.73 & 12.2 & 36.5 & 9146 & 8.8 \\
\hline & & \pm 10 & \pm 1.4 & $\pm 7 *$ & \pm 0.2 & \pm 8 & \pm 24.43 & \pm 1.8 & \pm 4.7 & \pm 2383 & \pm 10.7 \\
\hline & $\mathbf{T} 2$ & $\overline{87}$ & $\overline{6} 6$ & $\overline{6} 6$ & $\overline{0.8}$ & 22 & 68.30 & 12.2 & 36.3 & 11503 & 42.5 \\
\hline & & \pm 9 & \pm 7 & \pm 7 & \pm 0.2 & \pm 10 & \pm 25.45 & \pm 1.7 & \pm 4.3 & \pm 3195 & \pm 29.5 \\
\hline \multirow[t]{6}{*}{ HES } & $\mathbf{T 0}$ & 89 & 9.5 & $\overline{7} 6$ & 0.8 & 31 & 75 & 13.1 & 38.5 & $\overline{7} 432$ & 2.3 \\
\hline & & \pm 12 & \pm 1.6 & \pm 10 & \pm 0.2 & \pm 11 & \pm 35.82 & \pm 2.2 & \pm 6.1 & \pm 1515 & \pm 1.6 \\
\hline & T1 & 89 & $\overline{8} .4$ & $\overline{7} 2$ & 0.8 & $\overline{2} 6$ & 84 & $\overline{1} 1.6$ & 34.5 & $\overline{10223}$ & 5.6 \\
\hline & & \pm 9 & \pm 1.4 & $\pm 8^{*}$ & \pm 0.2 & \pm 5 & \pm 43.85 & \pm 1.7 & \pm 4 & \pm 3234 & \pm 4.2 \\
\hline & $\mathbf{T} 2$ & $\overline{84}$ & $\overline{6} 8$ & $\overline{6} 8$ & $\overline{0.7}$ & $\overline{2} 1$ & 73.16 & $\overline{12.1}$ & $\overline{3} 6 \pm$ & $\overline{1} 2235$ & $\overline{3} 2.2$ \\
\hline & & \pm 6 & \pm 8 & \pm 8 & \pm 0.2 & \pm 6 & \pm 37.36 & \pm 1.7 & $4 . \overline{4}$ & \pm 3315 & \pm 30 \\
\hline
\end{tabular}

MAP = Mean Arterial Pressure; SVV=Stroke Volume Variation; HR= Heart Rate; Cl= Clearance. T0=before anaesthesia induction, $\mathrm{T} 1=$ at the end of the operation, $\mathrm{T} 2=24$ hours postoperatively. Data are represented as number, mean $+\mathrm{SD}$.

Table 3. Demographics and perioperative data only in major operations

\begin{tabular}{llll}
\hline & HES-group & RL-group & p-value \\
\hline Operations & 11 & 12 &
\end{tabular}




\begin{tabular}{llll} 
Age (years) & $52 \pm 13$ & $47 \pm 10$ & 0.339 \\
Weight (kg) & $71 \pm 11$ & $73 \pm 11$ & \\
Height $(\mathbf{c m})$ & $162 \pm 7$ & $165 \pm 6$ & \\
Duration of surgery (min) & $79 \pm 18$ & $85 \pm 16$ & 0.357 \\
RL tot (ml) & $2273 \pm 743$ & $4558 \pm 679$ & $0.012^{*}$ \\
HES tot (ml) & $1191 \pm 333$ & 0 & \\
Urine output tot (ml) & $2759 \pm 688$ & $4004 \pm 1370$ & $0.013^{*}$ \\
\hline
\end{tabular}

Data are represented as number, mean + SD. ${ }^{*}$ p-value $<0.05$.

Table 4. Haemodynamic and haematological variables only in major operations

\begin{tabular}{llllllllll}
$\begin{array}{l}\text { MAP } \\
(\mathrm{mmHg})\end{array}$ & $\begin{array}{l}\text { SVV } \\
(\%)\end{array}$ & $\begin{array}{l}\text { HR } \\
\left(\mathrm{min}^{-1}\right)\end{array}$ & $\begin{array}{l}\text { Crea } \\
\text { tinine }\end{array}$ & $\begin{array}{l}\text { Urea } \\
(\mathrm{mg} / \mathrm{dl})\end{array}$ & $\begin{array}{l}\mathrm{Cl} \\
\text { creatinine }\end{array}$ & $\begin{array}{l}\mathrm{Hb} \\
(\mathrm{g} / \mathrm{dl})\end{array}$ & $\begin{array}{l}\text { Hct } \\
(\%)\end{array}$ & $\begin{array}{l}\text { WBC } \\
\left(\mathrm{mm}^{-3}\right)\end{array}$ & $\begin{array}{l}\text { CRP } \\
(\mathrm{mg} / \mathrm{dl})\end{array}$ \\
\hline
\end{tabular}




\begin{tabular}{|c|c|c|c|c|c|c|c|c|c|c|c|}
\hline \multirow{2}{*}{$\mathbf{R L}$} & \multirow[b]{2}{*}{ T0 } & \multirow[b]{2}{*}{$\begin{array}{l}89 \\
\pm 12.5\end{array}$} & \multirow[b]{2}{*}{$\begin{array}{l}9.91 \\
\pm 1.67\end{array}$} & \multirow[b]{2}{*}{$\begin{array}{l}73.83 \\
\pm 10.76\end{array}$} & \multicolumn{2}{|l|}{$(\mathrm{mg} / \mathrm{dl})$} & \multicolumn{3}{|l|}{$(\mathrm{ml} / \mathrm{min})$} & \multirow[b]{2}{*}{$\begin{array}{l}8953 \\
\pm 10549\end{array}$} & \multirow[b]{2}{*}{$\begin{array}{l}2.8 \\
\pm 1.83\end{array}$} \\
\hline & & & & & $\begin{array}{l}0.7 \\
\pm 0.1\end{array}$ & $28 \pm 12$ & $\begin{array}{l}114.3 \\
\pm 24.2\end{array}$ & $\begin{array}{l}12.8 \\
\pm 2\end{array}$ & $\begin{array}{l}39 \\
\pm 5.7\end{array}$ & & \\
\hline & T1 & $\begin{array}{l}87.33 \\
\pm 10.10 \\
87 \\
\pm 8.4\end{array}$ & $\begin{array}{l}8.66 \\
+1.557\end{array}$ & $\begin{array}{l}67.25 \\
\pm 8 \\
67 \\
\pm 7.73\end{array}$ & $\begin{array}{l}0.7 \\
\pm 0.1 \\
0.62 \\
\pm 0.08\end{array}$ & $\begin{array}{l}25 \pm 5 \\
14 \pm 6.29\end{array}$ & $\begin{array}{l}103.6 \\
\pm 35.6 \\
128.5 \\
\pm 20.7\end{array}$ & $\begin{array}{l}11.3 \\
\pm 1.6 \\
13,5 \\
\pm 7.53\end{array}$ & $\begin{array}{l}34.3 \\
+4.6 \\
32 \\
\pm 6.9\end{array}$ & $\begin{array}{l}9955 \\
+2758 \\
11935 \\
+3258\end{array}$ & $\begin{array}{l}7.2 \\
\pm 6.3 \\
58 \\
\pm 30.94\end{array}$ \\
\hline HES & T1 & $\begin{array}{l}85.81 \\
\pm 11.34 \\
92 \\
\pm 9.68 \\
83 \\
\pm 6.05\end{array}$ & $\begin{array}{l}9.72 \\
\pm 1.55 \\
8.45 \\
\pm 1.57\end{array}$ & $\begin{array}{l}77.1 \\
\pm 8.27 \\
73.63 \\
\pm 7.65 \\
69 \\
\pm 6.64 \\
\end{array}$ & $\begin{array}{l}0.7 \\
\pm 0.2 \\
0.8 \\
\pm 0.2 \\
0.66 \\
\pm 0.2 \\
\end{array}$ & $\begin{array}{l}28 \pm 10 \\
26 \pm 5 \\
19 \pm 6.06\end{array}$ & $\begin{array}{l}115.8 \\
+51.7 \\
97.9 \\
\pm 47.7 \\
126.8 \\
+58.2 \\
\end{array}$ & $\begin{array}{l}11.6 \\
\pm 2 \\
10.4 \\
\pm 1 \\
11 \\
\pm 1.15 \\
\end{array}$ & $\begin{array}{l}36.4 \\
\pm 5 \\
32 \\
\pm 2 \\
33 \\
\pm 2.7 \\
\end{array}$ & $\begin{array}{l}9010 \\
\pm 10797 \\
9867 \\
\pm 2795 \\
11732 \\
\pm 3170 \\
\end{array}$ & $\begin{array}{l}2.16 \\
\pm 1.83 \\
4.9 \\
\pm 4 \\
34.42 \\
\pm 29.65 \\
\end{array}$ \\
\hline
\end{tabular}

Data are represented as number, mean $+\mathrm{SD}$. T0=before anaesthesia induction, $\mathrm{T} 1=$ at the end of the operation, $\mathrm{T} 2=24$ hours postoperatively. 


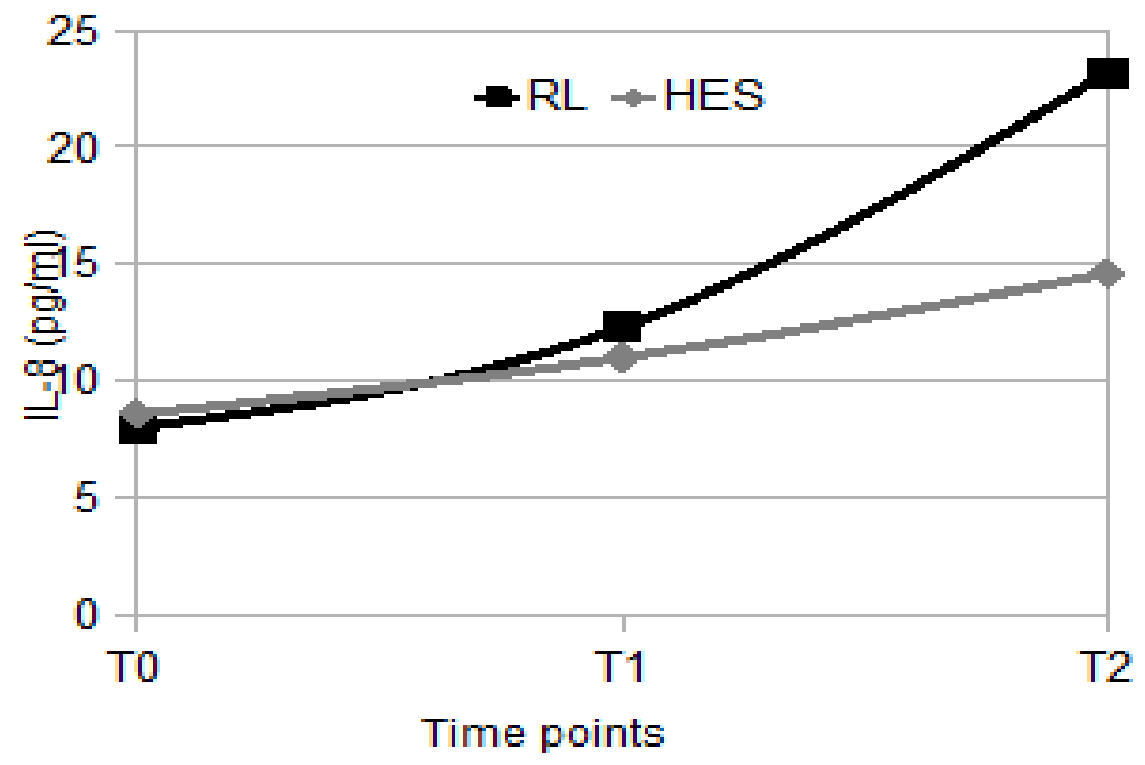

Fig, 1: IL-8 variation in all operations ( $\mathrm{p}<0.05)$. T0=before anaesthesia induction, $\mathrm{T} 1=$ at the end of operation, $\mathrm{T} 2=24$ hours postoperatively

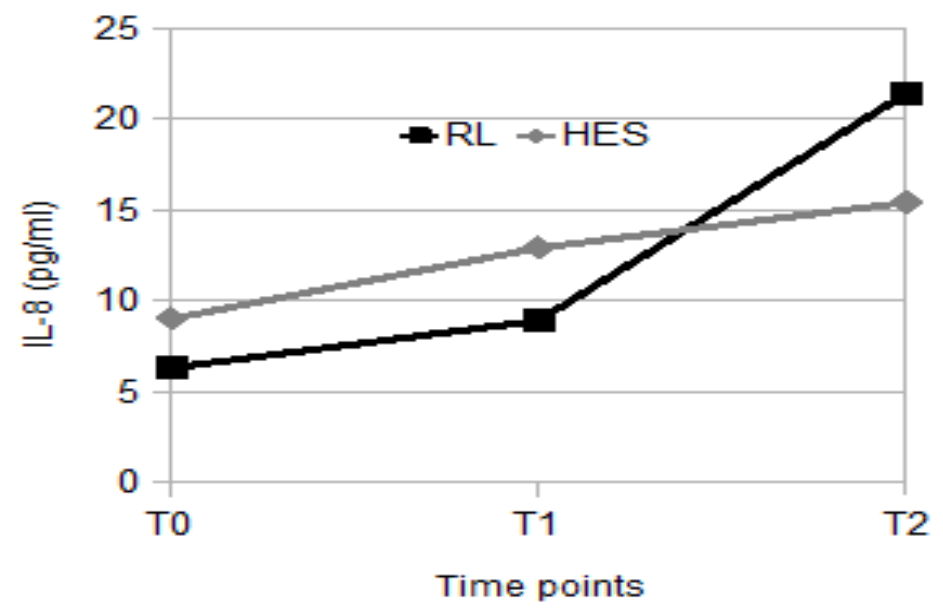


Fig. 2: IL-8 variation only in major operations $(\mathrm{p}<0.05)$. $\mathrm{T} 0=$ before anaesthesia induction, $\mathrm{T} 1=$ at the end of the operation, $\mathrm{T} 2=24$ hours postoperatively.

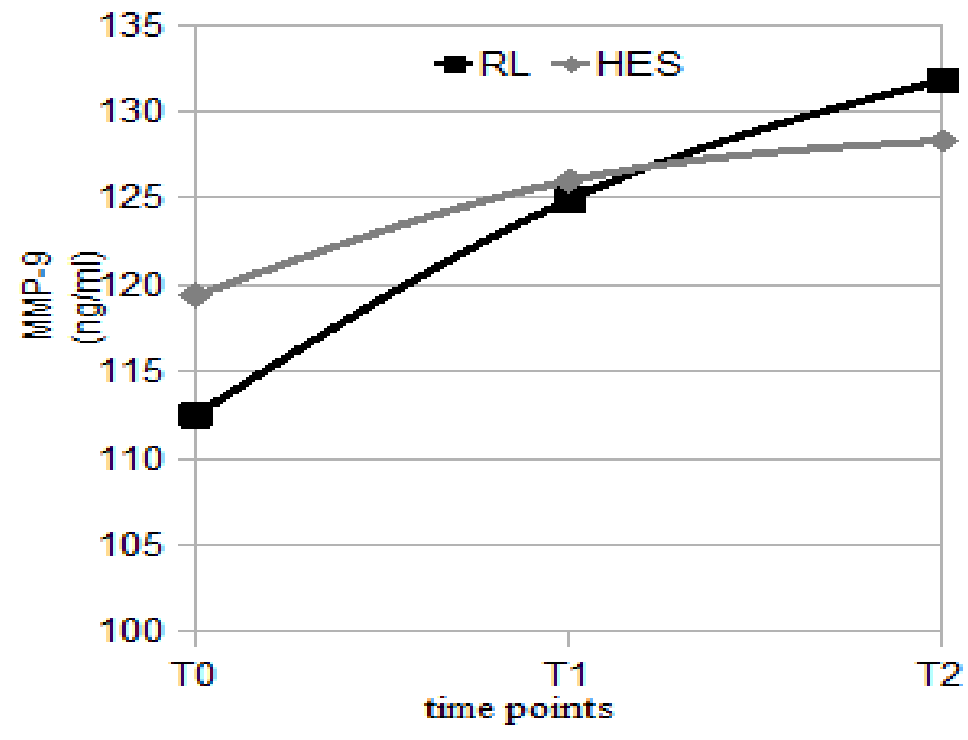

Fig. 3: MMP-9 variation in major operations $(\mathrm{p}<0.05)$. T0=before anaesthesia induction, $\mathrm{T} 1=$ at the end of the operation, $\mathrm{T} 2=24$ hours postoperatively. 